\title{
Effect of estradiol cypionate on estrus expression and pregnancy in timed artificially inseminated beef cows
}

\author{
Luiz Francisco Machado Pfeifer ${ }^{\mathrm{a}, *}$, Elizângela Mírian Moreira ${ }^{\mathrm{a}, \mathrm{f}}$, George Moreira da Silva ${ }^{\mathrm{a}, \mathrm{b}}$, \\ Vanessa Lemos de Souza ${ }^{\mathrm{a}, \mathrm{b}}$, Vanessa Rachele Ribeiro Nunes ${ }^{\mathrm{a}}$, Jéssica de Souza Andrade ${ }^{\mathrm{a}, \mathrm{c}}$, \\ Paulo Marcos Araújo Neves ${ }^{\mathrm{a}, \mathrm{d}}$, Rogerio Ferreira ${ }^{\mathrm{e}}$

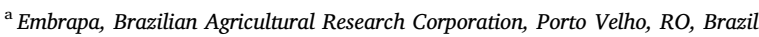 \\ ${ }^{\mathrm{b}}$ UNIR, Universidade Federal de Rondônia, Programa de Pós-Graduação em Desenvolvimento Regional e Meio Ambiente, Porto Velho, RO, Brazil \\ ${ }^{\mathrm{c}}$ Bionorte, Programa de Pós-Graduação em Biodiversidade e Biotecnologia, Porto Velho, RO, Brazil \\ ${ }^{\mathrm{d}}$ UNIR, Universidade Federal de Rondônia, Programa de Pós-Graduação em Ciências Ambientais, Rolim de Moura, RO, Brazil \\ ${ }^{\mathrm{e}}$ UDESC, Universidade do Estado de Santa Catarina, Chapecó, SC, Brazil \\ ${ }^{\mathrm{f}}$ FAPERO, Fundação de Amparo à Pesquisa de Rondônia, Porto Velho, RO, Brazil
}

\section{A R T I C L E I N F O}

\section{Keywords:}

Conception

Estrus

Gametes

Ovulation

\begin{abstract}
A B S T R A C T
Several studies have shown that cows displaying estrus before timed artificial insemination (TAI) are more likely to become pregnant. However, the most frequently used ovulation-inducing agents by South American beef operations, estradiol esters, may artificially induce estrus in treated cows. The hypotheses tested in the present study were: 1) estradiol cypionate (EC) treatment will induce estrus in ovariectomized cows, and 2) cows that exhibit estrus following administration of EC and eCG will have lower P/AI compared to those that do not receive EC. In Experiment 1, 14 ovariectomized cows were used in a cross-over design with an interval of $30 \mathrm{~d}$ between replicates. On Day 0, all cows received $2 \mathrm{mg}$ of estradiol benzoate and a CIDR device and $12.5 \mathrm{mg}$ of Dinoprost ( $\mathrm{PGF}_{2} \alpha$ analogue) on Day 7. On Day 9, the CIDR devices were removed and cows were placed at random into one of two experimental groups and administered either $0.5 \mathrm{~mL}$ of canola oil (Control, CTL group, $n=14$ ) or $1 \mathrm{mg}$ of EC (EC group, $n=14$ ). Estrotect estrus detection patches were used and cows were observed 4 times daily to determine the occurrence of estrus. More EC-treated cows showed estrus (12/14, 85.7\%) than canola oil-treated cows $(0 / 14 ; P<0,001)$. The interval from EC treatment to estrus was $46 \pm 3.7 \mathrm{~h}$. In Experiment 2, 804 postpartum Nelore cows were treated as in Experiment 1, except that all cows received 300 IU of equine chorionic gonadotrophin at CIDR removal, and were randomly divided into 3 groups: 1) EC group ( $n=269$ ) received $1 \mathrm{mg}$ i.m. of EC on Day 9; 2) EC-GnRH group $(n=269)$ received EC on Day 9, and were inseminated on observation of estrus, while those not showing estrus received GnRH on Day 11; and, 3) EstrusGnRH group $(n=266)$ did not receive EC on Day 9 and were inseminated on observation of estrus. Those in Groups 2 and 3 that did not show estrus received GnRH on Day 11 at the time of TAI. The proportion of cows showing estrus was greater $(P<0.0001)$ in EC $(68.7 \%, 185 / 269)$ and EC-GnRH $(57.2 \% ; 154 / 269)$ groups than in the Estrus-GnRH group (35.7\%, 95/266). However, no difference in P/AI was observed among the groups $(P=0.87)$. These results show that EC will induce estrus in ovariectomized cows, and that EC treatment increased the proportion of intact cows exhibiting estrus in a TAI protocol without reducing P/AI.
\end{abstract}

\section{Introduction}

Estradiol and progesterone-based protocols are commonly used in South American beef operations to synchronize follicular wave emergence and ovulation for timed artificial insemination (TAI; Sa Filho et al., 2009; Sa Filho et al., 2011). In such protocols, ovulations are usually induced with a low dose of estradiol ester concurrently with a progesterone device removal or $24 \mathrm{~h}$ later (Bo et al., 2003). Previous studies have demonstrated the efficacy of estradiol cypionate (EC) at the time of progesterone device removal to induce ovulation and to minimize the animal handling (Colazo et al., 2003; Ayres et al., 2008).

The occurrence of estrus after progesterone device removal and prior to TAI results in greater pregnancy per AI (P/AI; Sa Filho et al., 2010; Pfeifer et al., 2018; Nogueira et al., 2019). Cows that displayed

\footnotetext{
* Corresponding author.

E-mail address: luiz.pfeifer@embrapa.br (L.F.M. Pfeifer).
} 
estrus were 3.3 times more likely to become pregnant than those not detected in estrus (Sa Filho et al., 2010). However, estradiol esters have been shown to induce behavioral estrus. In an earlier study, nulliparous, ovariectomized cattle showed sexual behaviors typical of estrus after estradiol administration (Katz et al., 1980). In addition, in TAI programs greater P/AI have been reported for cows that display estrus than those that did not (Richardson et al., 2016). In this regard, fertility of cows that did not show estrus between progesterone insert removal and TAI was improved by delaying AI by $24 \mathrm{~h}$ (Thomas et al., 2014) or by administering GnRH concurrent with TAI in females that failed to express estrus (Thomas et al., 2014; Bishop et al., 2017). Similarly, the use of GnRH concurrent with TAI in Nelore cows raised under tropical conditions increased P/AI in those that did not display estrus (Sa Filho et al., 2011; Rodrigues et al., 2019). In addition, under circumstances with high incidence of anestrus, typically observed in grazing, suckled beef herds in Brazil, the efficacy of these treatments have been shown to be compromised (Sa Filho et al., 2013). Thus, equine chorionic gonadotropin (eCG) has been included in TAI protocols aiming to stimulate the ovarian follicular growth and, consequently, improving ovulation and P/AI (Baruselli et al., 2012).

Based on these considerations, it was hypothesized that eCG-treated cows showing estrus without EC are more likely to become pregnant than eCG + EC-treated cows. The objectives of this study were to determine whether EC will induce estrus in ovariectomized cows, and to determine the effect of EC on expression of estrus and P/AI in ovaryintact cows subjected to TAI protocols which included the addition of eCG treatment. The hypotheses were that EC will induce estrus in ovariectomized cows, and, that cows that exhibit estrus following EC administration will have lower P/AI compared to those that do not receive EC.

\section{Materials and methods}

The Committee for Ethics in Animal Experimentation from Embrapa, the Brazilian Agricultural Research Corporation, approved all of the procedures performed in the experiments described in this manuscript (Protocol 04/2017).

\subsection{Experiment 1}

This study was performed at the experimental research farm of Embrapa Rondônia (08, $\left.{ }^{0} 48^{\prime} 12^{\prime \prime} \mathrm{S}, 63,{ }^{0} 50^{\prime} 56^{\prime \prime} \mathrm{W}\right)$.

Fourteen ovariectomized crossbred cows, 3-7 years old, 450-650 kg in body weight, and with a 3-4 of body condition score (BCS; range $1-5$, where $1=$ emaciated and $5=$ obese; (Lowman et al., 1976)) were used. Cows were kept in an outdoor grazing system (Brachiaria brizantha pasture) with ad libitum access to mineral, salt and water.

All cows were submitted to a TAI protocol and received an intravaginal progesterone-releasing device $\left(1.9 \mathrm{~g}\right.$ progesterone, CIDR ${ }^{\circledR}$, Pfizer Animal Health, São Paulo, Brazil) plus $2 \mathrm{mg}$ of estradiol benzoate (Gonadiol $^{\circledR}$, Zoetis, São Paulo, Brazil) i.m. on Day 0. On Day 7, cows received $12.5 \mathrm{mg}$ i.m. of Dinoprost $\left(\mathrm{PGF}_{2} \alpha\right.$-analogue, Lutalyse ${ }^{\circledast}$, Zoetis, São Paulo,Brazil). On Day 9, the CIDR devices were removed and cows were randomly assigned to two treatment groups to receive: 1) $0.5 \mathrm{~mL}$ of canola oil (Control Group, $n=14$ ) i.m., or 2) $1 \mathrm{mg}$ i.m. of estradiol cypionate (EC Group, $n=14$; E.C.P ${ }^{\oplus}$, Pfizer Animal Health, São Paulo, Brazil). A $2 \times 2$ cross-over design in which all cows received both treatments was used. The interval between replicates was 1 month.

Estrus detection aids (Estrotect ${ }^{\circledR}$, Rockway Inc., Spring Valley, WI, USA) were placed on all cows on Day 9. Cows were observed for Estrotect $^{\circledR}$ activation four times daily, from Days 9 to 13 .

\subsection{Experiment 2}

This experiment was performed on a commercial farm in the northern region of Brazil $\left(08,{ }^{0} 48^{\prime} 12^{\prime \prime} \mathrm{S}, 63,{ }^{0} 50^{\prime} 56^{\prime \prime} \mathrm{W}\right)$. In this experiment, 804 Nelore cows, 40 to 60 days postpartum with a BCS ranging from 2.5 to 3.5 were enrolled. The cows were maintained on a grazing system (Brachiaria brizantha) with ad libitum access to mineral, salt and water.

Cows were submitted to the same TAI protocol as in Experiment 1. However, on Day 9 when CIDR $^{\circledR}$ devices were removed, all cows received 300 IU i.m. of equine chorionic gonadotrophin (eCG, Novormon $^{\circledR}$, Zoetis, São Paulo, Brazil). All cows were painted with a chalk marker in the sacrococcigeal region to identify cows that showed estrus, and were randomly assigned to one of three treatments groups: 1) EC group $(n=269)$; cows received $1 \mathrm{mg}$ i.m. of EC on Day $9\left(\mathrm{ECP}^{\circledR}\right.$, Pfizer Animal Health, São Paulo, Brazil) and were TAI on Day 11; 2) ECGnRH group $(n=269)$; cows received $1 \mathrm{mg}$ i.m. of EC on Day 9 and cows that did not display estrus between $\mathrm{CIDR}^{\circledR}$ removal and TAI on Day 11 received GnRH (10.5 $\mu$ g i.m. of buserelin acetate, Gonaxal ${ }^{\circledR}$, Biogenesis Bagó, Buenos Aires, Argentina) at that time; and 3) EstrusGnRH group $(n=266)$; cows did not receive EC on Day 9, and cows that did not display estrus between $\mathrm{CIDR}^{\circledast}$ removal and TAI on Day 11 received GnRH at that time. On Day 11, estrus was evaluated at the time of TAI, and deemed to have occurred in cows without a tail-head chalk mark. A single inseminator performed all inseminations, and semen straws from five bulls of proven fertility were equally distributed among the three treatment groups.

Ultrasound examinations were performed at TAI in a subset $(n=138)$ in order to measure the diameter of the pre-ovulatory follicle (POF), and at 30 days post-TAI to assess pregnancy status in all cows. Visualization of the embryonic vesicle and detection of the embryo were the positive criteria for determining pregnancy status.

\subsection{Statistical analyses}

All statistical analyses were performed using SAS software. The statistical model included the effects of treatment, bull, body condition score (BCS) and parity. The variables bull, BCS, and parity had no significant effect on the model and were excluded from it. The diameter of the ovulatory follicle was analyzed using analysis of variance (PROC GLIMMIX) and means were compared among groups using Tukey's test. Proportions with dichotomous outcomes (yes or no), such as estrus detection and P/AI, were analyzed using Chi-squared tests. The relationship between the diameter of the POF at TAI on the probability of cows displaying estrus was determined. Logistic regression curves were created using the coefficients provided by the interactive data analysis from SAS and the formula $y=\exp (\alpha x+b) /[1+\exp (\alpha x+b)]$. The results are expressed as means \pm SEM or as percentages. In all analyses, differences were considered significant when $P \leq 0.05$, whereas 0.05 $<P \leq 0.10$ were considered tendencies.

\section{Results}

\subsection{Experiment 1}

The estrus responses in Experiment 1 are summarized in Table 1. The number of ovariectomized cows showing estrus was greater in the EC group than in the canola oil group $(P<0.001)$. In those showing estrus in the EC group, the mean interval from $\mathrm{CIDR}^{\circledast}$ device removal was $46 \pm 3.7 \mathrm{~h}$.

The distribution and percentage of ovariectomized cows showing estrus after CIDR removal in the EC group are shown in Fig. 1.

\subsection{Experiment 2}

Ovarian and estrus responses and P/AI in Experiment 2 are summarized in Tables 2 and 3. The P/AI did not differ among the groups $(P=0.87)$.

The proportion of cows that showed estrus during the interval from CIDR device removal to TAI was greater in EC and EC-GnRH groups 
Table 1

Estrus responses of ovariectomized cows treated with $1 \mathrm{mg}$ of EC or $0.5 \mathrm{~mL}$ of canola oil (Control) after exposure to progesterone devices.

\begin{tabular}{|c|c|c|c|}
\hline Variable & Groups & & \\
\hline & $\mathrm{EC}^{*}$ & Control* & $P$ value \\
\hline Expression of estrus\%, (n/n) & $85.7 \%(12 / 14)$ & $0 \%(0 / 14)$ & $P<0,001$ \\
\hline Interval to estrus (h) ${ }^{a}$ & $46 \pm 3.7$ & - & \\
\hline
\end{tabular}

${ }^{\text {a }}$ Interval from $\mathrm{CIDR}^{\circledR}$ device removal to estrus detection.

* All cows received a CIDR device plus $2 \mathrm{mg}$ of estradiol benzoate on Day 0 and $12.5 \mathrm{mg}$ of PGF analogue (Dinoprost) on Day 7. On Day 9, the CIDR devices were removed and cows were assigned to two treatment groups in a cross-over design to receive $0.5 \mathrm{~mL}$ of canola oil (Control Group, $n=14$ ) or $1 \mathrm{mg}$ of estradiol cypionate (EC Group, $n=14$; E.C.P ${ }^{\circledR}$ ).

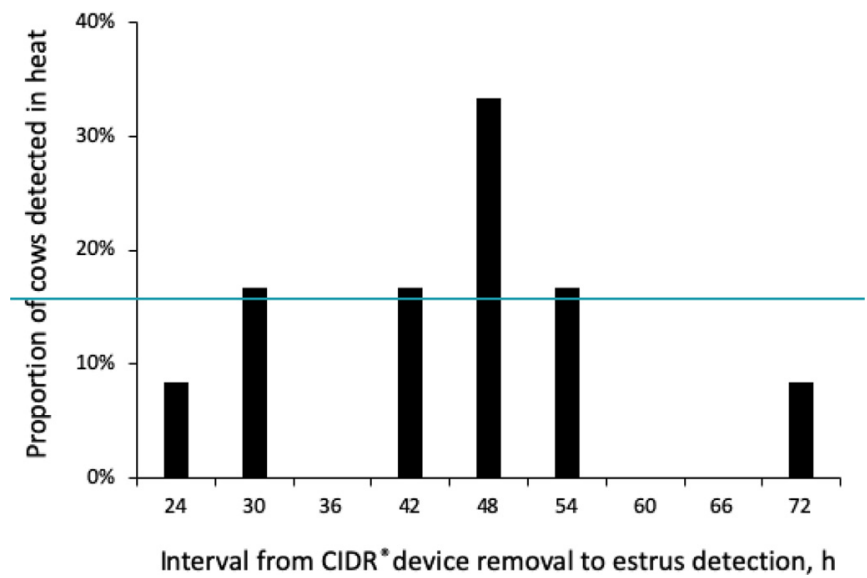

Fig. 1. Distribution and percentage of ovariectomized cows showing estrus after CIDR removal in the EC group.

than in the Estrus-GnRH group $(P<0.001$; Table 2). Cows that showed estrus had a greater $(P=0.04)$ follicular diameter at TAI $(13.8 \pm 0.3$ vs. $13.0 \pm 0.3 \mathrm{~mm})$, and greater $(P<0.001) \mathrm{P} / \mathrm{AI}$ than those that did not display estrus $(64.3 \%, 279 / 434$ vs. $51.9 \%, 192 / 370)$.

Considering only the cows that showed estrus within each group, there was no difference in $\mathrm{P} / \mathrm{AI}$ among the groups $(P=0.44)$. Similarly, in cows that did not show estrus, $\mathrm{P} / \mathrm{AI}$ did not differ among groups $(P=0.69$; Table 3$)$.

The diameter of the POF at TAI did not differ among the groups $(P=0.12)$. However, the probability of cows showing estrus increased with increasing POF diameter $(P=0.04$; Fig. 2).

\section{Discussion}

The results of the current study supported the hypothesis that EC is able to induce estrus in ovariectomized cows. However, the hypothesis that cows that exhibit estrus following EC administration will have lower P/AI compared to those that do not receive EC was not supported.

The use of ovariectomized cows in Experiment 1 clearly showed that EC induces behavioral estrus in ovariectomized cows as has been previously described (Katz et al., 1980). Different doses of estradiol-17 $\beta$ (200, 400, and $800 \mu \mathrm{g}$ ), administered to ovariectomized nulliparous cattle, induced a full repertoire of sexual behavioral patterns associated with the female in estrus (Katz et al., 1980). In Experiment 1, EC administration induced estrus in 64\% (9/14) of the cows within $48 \mathrm{~h}$ after treatment, which indicates that, in a conventional TAI protocol which included the administration of EC, most of the cows would have exhibited estrus before TAI. However, when nulliparous ovariectomized cattle were treated with estradiol-17 $\beta$, the interval from treatment to the first stand to be mounted is $25.4 \pm 0.8 \mathrm{~h}$ (Katz et al., 1980). Prior exposure to progesterone has also been shown to affect the interval to estrus after EC administration in intact dairy cows. In dairy cows subjected to the Heatsynch protocol, administration of $1 \mathrm{mg}$ of EC resulted in the expression of estrus in $19 \pm 5 \mathrm{~h}$ when CIDR insert was given between GnRH and PGF treatment while the interval was $33 \pm 4 \mathrm{~h}$ when the CIDR was not given (Stevenson et al., 2004). Moreover, when $0.25 \mathrm{mg}$ of EC was given concurrent with GnRH in the Ovsynch protocol, cows had higher serum estradiol concentrations at 6 and $12 \mathrm{~h}$ after treatment, than when cows did not receive EC (Sellars et al., 2006). Collectively, these results demonstrate that EC is able to induce estrus in ovariectomized and intact cows.

Estradiol esters are commonly used at the end of estradiol-progesterone-based TAI protocols to induce LH release and synchronize ovulation. A rise in circulating LH concentration has been reported to occur $40 \mathrm{~h}$ after EC treatment in ovariectomized beef heifers submitted to an estradiol-progesterone-based protocol (Sales et al., 2012). However, administration of EC increased the proportion of Nelore cows showing estrus after progesterone device removal, compared to the administration of only GnRH as an ovulatory stimulus (Sa Filho et al., 2011). As observed in the present study, the proportion of cows that showed estrus was greater in EC-treated cows. In contrast, an unexpected difference in estrus manifestation between the EC and EC-GnRH groups was observed. Although not different, the diameter of the POF in the ECGnRH group was $\sim 1 \mathrm{~mm}$ smaller than cows in the EC group. This could explain the difference in estrus rate between these experimental groups.

Previous reports (Sa Filho et al., 2011; Pfeifer et al., 2018; Rodrigues et al., 2019), have indicated that cows that show estrus behavioral were more likely to become pregnant when TAI protocols are used. However, this effect was not detected in the present study when $\mathrm{P} / \mathrm{AI}$ was compared between cows that displayed estrus and cows that did not display estrus within group. The failure to show a differences may be due to insufficient numbers of cows in the treatment groups. However, it has been reported that cows showing estrus had larger follicular diameters at TAI, and greater P/AI than those that did not show estrus (Sa Filho et al., 2011). The occurrence of standing estrus has been reported to be associated with peak circulating estradiol concentrations (Allrich, 1994), which may influence fertilization by altering the uterine environment (Hawk, 1983). Following the occurrence of standing estrus, the uterine environment has been shown to be modified to enhance sperm motility and longevity (Acott and Carr, 1984; Jones and Bavister, 2000). Thus, elevated estradiol levels from either endogenous or exogenous sources may play an important role in sperm transport and the sustained viability of sperm prior to ovulation and fertilization (Sa Filho et al., 2011) explaining the greater $\mathrm{P} / \mathrm{AI}$ observed in cows that displayed estrus.

Table 2

Diameter of preovulatory follicles, proportion of cows in estrus, and pregnancy per AI of cows treated with EC, EC-GnRH or Estrus-GnRH in Experiment 2.

\begin{tabular}{|c|c|c|c|c|}
\hline & \multicolumn{4}{|l|}{ Group } \\
\hline & EC & EC-GnRH & Estrus-GnRH & $\mathrm{P}$ value \\
\hline Preovulatory follicle at TAI, mm (n)* & $13.7 \pm 0.3(47)$ & $12.8 \pm 0.3(43)$ & $13.7 \pm 0.3(48)$ & 0.12 \\
\hline Proportion of cows that showed estrus, $\%$ (n/total) & $68.7^{\mathrm{A}}(185 / 269)$ & $57.2^{\text {B }}(154 / 269)$ & $35.7^{\mathrm{C}}(95 / 266)$ & $<0.001$ \\
\hline Pregnancy per AI,\% (n/total) & $58.7(158 / 269)$ & $59.8(161 / 269)$ & $57.1(152 / 266)$ & 0.87 \\
\hline
\end{tabular}

Within row, different superscripts indicate differences among groups $(P<0.05)$.

* Number of cows evaluated in each group. 
Table 3

Pregnancy per AI (P/AI) based on expression of estrus in cows treated with EC, EC-GnRH, or Estrus-GnRH. .

\begin{tabular}{|c|c|c|c|c|}
\hline & Group & & & \\
\hline & $\mathrm{EC}$ & EC-GnRH & Estrus-GnRH & $P$ value \\
\hline $\mathrm{P} / \mathrm{AI}$ in cows that showed estrus, $\%$ (n/total) & $61.6(114 / 185)$ & $68.2(105 / 154)$ & $63.3(60 / 95)$ & 0.44 \\
\hline $\mathrm{P} / \mathrm{AI}$ in cows that did not display estrus, $\%$ (n/total) & $52.4(44 / 84)$ & $48.7(56 / 115)$ & $53.8(92 / 171)$ & 0.69 \\
\hline $\mathrm{P}_{\text {value }}{ }^{* *}$ & 0.15 & $<0.01$ & 0.13 & \\
\hline
\end{tabular}

* Comparison among groups.

** Comparison between cows that showed estrus and cows that did not show estrus.

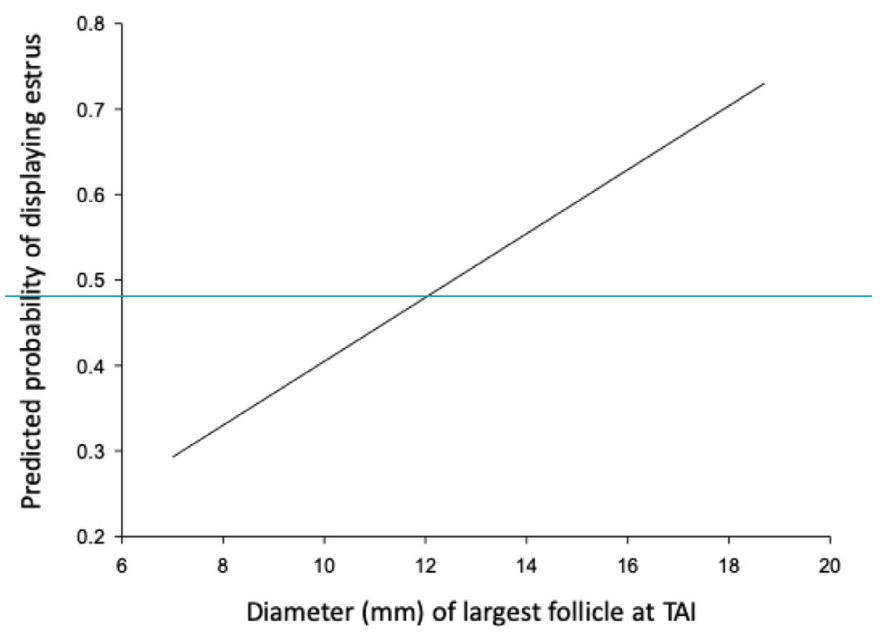

Fig. 2. Probability of estrus occurrence in suckled Bos indicus cows according to the diameter of the largest follicle (LF) at FTAI in Experiment 2 [probability of estrus occurrence $=\exp (0.031+0.0374 \times$ diameter of the $\mathrm{LF} / 1+\exp$ $(0.031+0.0374 \times$ diameter of the LF); $P=0.04)]$.

More recently, alternatives have been developed to take advantage of the expression of estrus to improve fertility in TAI protocols. One such alternative, split-time artificial insemination (STAI), involves delaying AI by $20-24 \mathrm{~h}$ for females failing to show estrus prior to the standard time of TAI. This approach has been shown to be an effective means of optimizing pregnancy rates while utilizing TAI (Thomas et al., 2014).

In cows that were examined by ultrasound $(n=138)$, in Experiment 2,3 cows that showed estrus had a follicle $\leq 8 \mathrm{~mm}$ in the ovary at the time of TAI. When the cows in this study were categorized based on the diameter of the POF, as described previously (Pfeifer et al., 2015; 2019), $46 \%$ (28/61) of the cows with small follicles $(<13 \mathrm{~mm})$ exhibited estrus. Moreover, in cows that had POF $\leq 10 \mathrm{~mm}$ at TAI, $27 \%$ showed behavioral estrus between progesterone device removal and TAI. In contrast, none of the cows with POF $\leq 11.5 \mathrm{~mm}$ in the EstrusGnRH group showed estrus. However, if a POF diameter of $11.5 \mathrm{~mm}$ is used as a cut-off, $40 \%$ and $44 \%$ of the cows in the EC and EC-GnRH groups respectively, exhibited estrus. These results support our hypothesis that EC treatment can induce estrus in beef cows independently of the ovarian response.

Cows in Experiment 2 were treated with 300 IU of eCG on Day 9 of the TAI protocol. Previous studies have demonstrated that eCG treatment of anestrus cows under nutritional stress increased follicular growth rate, the diameter of the dominant follicle at TAI, and pregnancy rates (Baruselli et al., 2004; Sa Filho et al., 2009). Thus, one could speculate that the use of eCG in Experiment 2 of the present study may have affected estrus response of treated cows. Nevertheless, Experiment 2 was performed at commercial beef operations and thus, we used standard TAI protocol for suckled beef cows which typically includes the use of eCG. Indeed, cows treated with eCG and EC, at progesterone insert removal, exhibited a greater occurrence of estrus than cows only treated with EC (Pessoa et al., 2016). Differences in protocols between Experiments 1 and 2 were mitigated because eCG was distributed equally among groups in Experiment 2. However, further studies are needed to determine if eCG could affect the proportion of EC-treated cows showing estrus.

$\mathrm{GnRH}$ has been used as an alternative in cows that do not exhibit estrus between progesterone device removal and TAI. Interestingly, $35.7 \%$ of the cows from the Estrus-GnRH cohort underwent TAI without receiving $\mathrm{GnRH}$ to induce ovulation, and these cows achieved $63 \%$ of $\mathrm{P} / \mathrm{AI}$. In contrast, the remaining $64 \%$ of cows from this group were treated with $\mathrm{GnRH}$ at the time of TAI to induce ovulation. As compared to cows treated with EC (i.e. EC vs. EC-GnRH) in this study, GnRH did not improve pregnancy rates in cows that did not show estrus. In addition, it has been shown that GnRH administration is unnecessary in cows exhibiting estrus prior to TAI (Hill et al., 2016; Bishop et al., 2017). In contrast, others have observed that the administration of $\mathrm{GnRH}$ in estradiol progesterone-based protocols can be used as an alternative to improve conception rates in Bos indicus beef cows, particularly those with no or little evidence of behavioral estrus (Rodrigues et al., 2019), and Sa Filho et al. (2010) reported that the administration of GnRH at TAI avoided delayed ovulations, improving synchronization of ovulation and pregnancy rates. GnRH treatment at the time of TAI may induce a preovulatory LH surge and ovulation in cows that would have had delayed ovulation. Nonetheless, Shephard et al. (2014) suggests that the results of GnRH administration at the time of $\mathrm{AI}$ are limited, and that the positive effect in lactating dairy cows may be mediated through the improved oocyte maturation and/or improved luteal function, rather than by reducing AI-to-ovulation intervals. Finally, although a large study, performed with 937 beef cows revealed that GnRH increases $\mathrm{P} / \mathrm{AI}$ in cows categorized as having low or no expression of behavioral estrus (Rodrigues et al., 2019), more research is necessary to determine the need for GnRH in cows that do not show estrus in an estradiol progesterone-based TAI protocols.

Earlier, Sa Filho et al. (2010), observed that $57 \%$ of the cows treated with EC were detected in estrus between the P4 device removal and TAI. In contrast, considering only cows treated with EC in the present study (e.g. EC and EC-GnRH groups), $63 \%$ of the cows exhibited estrus. This effect may be due to the use of different doses of EC between studies (0.6 mg vs. $1 \mathrm{mg}$ ). More recently, Nogueira et al. (2019) observed that $41 \%$ of the cows treated EC using the same dose as described in the present study were detected in estrus. We, therefore, infer that the greater estrus rate observed in the present study was probably due to the adequate BCS of the cows; $82 \%(659 / 804)$ of the cows had a BCS > 2.75 (scale 1 - 5; Pfeifer et al., 2017) whereas cows raised in the Brazilian wetlands (Pantanal region) usually have low BCS (only $58 \%$ of the cows had BCS > 2.75). These evidence may explain why, in the present study, a greater proportion of cows were detected in estrus between P4 device removal and TAI compared to other studies.

\section{Conclusions}

In summary, EC used as a means of inducing ovulation in estradiolprogesterone-based TAI protocols has also been shown to induce estrus in ovariectomized cows. The results from Experiment 2 showed that EC could be removed from the TAI protocol when a combination of estrus detection and GnRH administration was used. In the present study, 
behavioral estrus without the use of EC treatment was used to increase pregnancy rates in cattle subjected to TAI. However, P/AI among groups was similar. Perhaps AI in cows that displayed estrus should be postponed in order to time AI in relation to ovulation more precisely. Therefore, more studies aiming to better understand the factors influencing the occurrence of estrus, ovulation and pregnancy, following estradiol-progesterone-based synchronization protocols that included the use of eCG, are necessary before concluding that the removal of EC from the protocol is beneficial for postpartum beef cows subjected to TAI.

\section{Declaration of Competing Interest}

We declare that there are no conflicts of interests in this study.

\section{Acknowledgments}

This study received funding support from Embrapa (MP1/PC3 Project n. 01.03.14.011.00.00) and from CNPq (Universal Project n: 407307/2016-8). We thank Dr. Reuben Mapletoft for kindly editing the manuscript.

\section{References}

Acott, T.S., Carr, D.W., 1984. Inhibition of bovine spermatozoa by caudal epididymal fluid: II. Interaction of $\mathrm{pH}$ and a quiescence factor. Biol. Reprod. 30, 926-935.

Allrich, R.D., 1994. Endocrine and neural control of estrus in dairy cows. J. Dairy Sci. 77, $2738-2744$.

Ayres, H., Martins, C.M., Ferreira, R.M., Mello, J.E., Dominguez, J.H., Souza, A.H., Valentin, R., Santos, I.C., Baruselli, P.S., 2008. Effect of timing of estradiol benzoate administration upon synchronization of ovulation in suckling nelore cows (Bos indicus) treated with a progesterone-releasing intravaginal device. Anim. Reprod. Sci. 109, 77-87.

Baruselli, P.S., Reis, E.L., Marques, M.O., Nasser, L.F., Bo, G.A., 2004. The use of hormonal treatments to improve reproductive performance of anestrous beef cattle in tropical climates. Anim. Reprod. Sci. 82-83, 479-486.

Baruselli, P.S., Sales, J.N., Sala, R.V., Vieira, L.M., Sa Filho, M.F., 2012. History, evolution and perspectives of timed artificial insemination programs in brazil. Anim. Reprod. 9, 139-152.

Bishop, B.E., Thomas, J.M., Abel, J.M., Poock, S.E., Ellersieck, M.R., Smith, M.F., Patterson, D.J., 2017. Split-time artificial insemination in beef cattle: III. comparing fixed-time artificial insemination to split-time artificial insemination with delayed administration of gnrh in postpartum cows. Theriogenology 99, 48-52.

Bo, G.A., Baruselli, P.S., Martinez, M.F., 2003. Pattern and manipulation of follicular development in bos indicus cattle. Anim. Reprod. Sci. 78, 307-326.

Colazo, M.G., Kastelic, J.P., Mapletoft, R.J., 2003. Effects of estradiol cypionate (ECP) on ovarian follicular dynamics, synchrony of ovulation, and fertility in CIDR-based, fixed-time ai programs in beef heifers. Theriogenology 60, 855-865.

Hawk, H.W., 1983. Sperm survival and transport in the female reproductive tract. J. Dairy Sci. 66 2645-2460.

Hill, S.L., Grieger, D.M., Olson, K.C., Jaeger, J.R., Dahlen, C.R., Crosswhite, M.R., Pereira, N.N., Underdahl, S.R., Neville, B.W., Ahola, J., Fischer, M.C., Seidel, G.E., Stevenson, J.S., 2016. Gonadotropin-releasing hormone increased pregnancy risk in suckled beef cows not detected in estrus and subjected to a split-time artificial insemination program. J. Anim. Sci. 94, 3722-3728.

Jones, J.M., Bavister, B.D., 2000. Acidification of intracellular pH in bovine spermatozoa suppresses motility and extends viable life. J. Androl. 21, 616-624.

Katz, L.S., Oltenacu, E.A., Foote, R.H., 1980. The behavioral responses in ovariectomized cattle to either estradiol, testosterone, androstenedione, or dihydrotestosterone.
Horm. Behav. 14, 224-235.

Lowman, B.G., Scott, N.A., Somervalle, S.H., 1976. Condition scoring of cattle. Edinburgh 6, 1-31.

Nogueira, E., Silva, M.R., Silva, J.C.B., Abreu, U.P.G., Anache, N.A., Silva, K.C., Cardoso, C.J.T., Sutovsky, P., Rodrigues, W.B., 2019. Timed artificial insemination plus heat I: effect of estrus expression scores on pregnancy of cows subjected to progesteroneestradiol-based protocols. Animal 1-8.

Pessoa, G.A., Martini, A.P., Carloto, G.W., Rodrigues, M.C.C., Claro Junior, I., Baruselli, P.S., Brauner, C.C., Rubin, M.I.B, Correa, M.N, Leivas, F.G., Sa Filho, M.F., 2016. Different doses of equine chorionic gonadotropin on ovarian follicular growth and pregnancy rate of suckled BOS taurus beef cows subjected to timed artificial insemination protocol. Theriogenology 85, 792-799.

Pfeifer, L.F.M., Castro, N.A., Melo, V.T., Neves, P.M., Cestaro, J.P., Schneider, A., 2015 Timed artificial insemination in blocks: a new alternative to improve fertility in lactating beef cows. Anim. Reprod. Sci. 163, 89-96.

Pfeifer, L.F., Castro, N.A., Neves, P.M., Cestaro, J.P., Siqueira, L.G., 2017. Development and validation of an objective method for the assessment of body condition scores and selection of beef cows for timed artificial insemination. Liv. Sci. 197, 82-87.

Casanova daPfeifer, L.F.M., Rodrigues, W.B., Silva, K., Anache, N.A., Castro, N.A., Castilho, E.M., Nogueira, E., 2018. Different protocols using PGF2alpha as ovulation inducer in nelore cows subjected to estradiol-progesterone timed AI based protocols. Theriogenology 120, 56-60.

Pfeifer, L.F.M., Junior, J.S.O., Potiens, J.R., 2019. Effect of sperm kinematics and size of follicle at ovulation on pregnancy rate after timed ai of beef cows. Anim. Reprod. Sci. 201, 55-62.

Richardson, B.N., Hill, S.L., Stevenson, J.S., Djira, G.D., Perry, G.A., 2016. Expression of estrus before fixed-time AI affects conception rates and factors that impact expression of estrus and the repeatability of expression of estrus in sequential breeding seasons. Anim. Reprod. Sci. 166, 133-140.

Rodrigues, W.B., Silva, A.S., Silva, J.C.B., Anache, N.A., Silva, K.C., Cardoso, C.J.T. Garcia, W.R., Sutovsky, P., Nogueira, E., 2019. Timed artificial insemination plus heat II: gonadorelin injection in cows with low estrus expression scores increased pregnancy in progesterone/estradiol-based protocol. Animal 1-6.

Filho, Sa, F., M., Crespilho, A.M., Santos, J.E., Perry, G.A., Baruselli, P.S., 2010. Ovarian follicle diameter at timed insemination and estrous response influence likelihood of ovulation and pregnancy after estrous synchronization with progesterone or progestin-based protocols in suckled BOS indicus cows. Anim. Reprod. Sci. 120, 23-30.

Filho, Sa, F., M., Santos, J.E., Ferreira, R.M., Sales, J.N., Baruselli, P.S., 2011. Importance of estrus on pregnancy per insemination in suckled BOS indicus cows submitted to estradiol/progesterone-based timed insemination protocols. Theriogenology 76, 455-463.

Sa Filho, M.F., Penteado, L., Reis, E.L., Reis, T.A., Galvão, K.N., Baruselli, P.S., 2013. Timed artificial insemination early in the breeding season improves the reproductive performance of suckled beef cows. Theriogenology 79, 625-632.

Sa Filho, O.G., Meneghetti, M., Peres, R.F., Lamb, G.C., Vasconcelos, J.L., 2009. Fixedtime artificial insemination with estradiol and progesterone for BOS indicus cows II: strategies and factors affecting fertility. Theriogenology 72, 210-218.

Sales, J.N., Carvalho, J.B., Crepaldi, G.A., Cipriano, R.S., Jacomini, J.O., Maio, J.R., Souza, J.C., Nogueira, G.P., Baruselli, P.S., 2012. Effects of two estradiol esters (benzoate and cypionate) on the induction of synchronized ovulations in bos indicus cows submitted to a timed artificial insemination protocol. Theriogenology 78 , $510-516$.

Sellars, C.B., Dalton, J.C., Manzo, R., Day, J., Ahmadzadeh, A., 2006. Time and incidence of ovulation and conception rates after incorporating estradiol cypionate into a timed artificial insemination protocol. J. Dairy Sci. 89, 620-626.

Shephard, R.W., Morton, J.M., Norman, S.T., 2014. Effects of administration of gonadotropin-releasing hormone at artificial insemination on conception rates in dairy cows. Anim. Reprod. Sci. 144, 14-21.

Stevenson, J.S., Tiffany, S.M., Lucy, M.C., 2004. Use of estradiol cypionate as a substitute for gnrh in protocols for synchronizing ovulation in dairy cattle. J. Dairy Sci. 87, 3298-3305.

Thomas, J.M., Lock, S.L., Poock, S.E., Ellersieck, M.R., Smith, M.F., Patterson, D.J., 2014. Delayed insemination of nonestrous cows improves pregnancy rates when using sexsorted semen in timed artificial insemination of suckled beef cows. J. Anim. Sci. 92, $1747-1752$. 